\title{
Healthy publics as multi-species matters: solidarity with people's pets in One Health promotion
}

\author{
Melanie Rock (iD) ${ }^{1 \times} \&$ Gwendolyn Blue ${ }^{1}$
}

Climate change is contributing to local disasters, and pets increasingly figure in mediated views and responses. By theorizing such responses, we expand on the conceptualization of "healthy publics". In our view, healthy publics can arise from multi-species entanglements, out of which enactments of solidarity may emerge. Such enactments may encompass people with pets, as well as the pets themselves. Such enactments are selective, however, because they highlight certain lives and vulnerable situations while obscuring others. To develop this line of inquiry, we treated a major flood that took place in 2013 as a case-study. Participantobservation, social media, and qualitative interviews informed our analysis. During the immediate responses to the flood, a particular human-animal dyad became emblematic of people helping one another and their pets. As the floodwaters subsided, media reports helped to coordinate a public response to shelter people and pets on a temporary basis. Yet in the months following the flood, housing insecurity worsened for people with pets. With the passage of time, media coverage became instrumental in resolving housing crises for people with pets, but only on a case-by-case basis. Housing security for people with pets, as a policy issue, remains disconnected from planning to improve resilience overall and to enhance preparedness for disasters. Our analysis highlights the value of engaged research in foregrounding policy issues that influence the lives of people and pets. We conclude that, to be healthy, multi-species publics must entertain questions about whose lives come to matter most. The relative health of a public pivots on the extent to which policies emphasize inclusion and equity. By extension, some publics qualify as unhealthy, which could seem like a provocative claim. At this historical juncture, we feel compelled to defend decision-making process that attend not only to differences of opinion, but also to differences in possible ways of being in the world.

\footnotetext{
${ }^{1}$ University of Calgary, Calgary, AB, Canada. ${ }^{\circledR e m a i l: ~ m r o c k @ u c a l g a r y . c a ~}$
} 


\section{Introduction}

s described by Hinchliffe et al. (2018), the concept of a "healthy public" could radically transform research and practice in public health. Healthy publics consist of "dynamic collectives of people, ideas, and environments that can enable health and well-being" (Hinchliffe et al., 2018, p. 2). Through public experimentation, "social and material relations" are built, repaired, staged, and sustained (Hinchliffe et al., 2018, p. 1). Public experimentation and engaged research "can shift the focus of public health away from populations and individuals as passive targets for policy, and away from the view that culture acts as a barrier to efficient biomedical innovation" (Hinchliffe et al., 2018, p. 2). Put another way, healthy publics provide a "conceptual platform", one that "underline[s] the importance of social, cultural, and environmental movements and relations in providing the conditions for healthy outcomes across the lifecourse" (Hinchliffe et al., 2018, p. 2). Social scientists' engagement in political issues can help to render events into public experiments, from which lessons for policy and practice can be drawn. Engaged scholarship is especially crucial whenever "publics remain fragile and buffeted by competing and often more powerful public formations" (Hinchliffe et al., 2018, p. 1).

To develop these arguments, we integrate Dewey's (1991 [1927]) views on experimentation and on publics, together with insights from human-animal studies and from science and technology studies. Dewey (1991 [1927], p. 27) defined "a public" as "all those who are affected by the indirect consequences of transactions to such an extent that it is deemed necessary to have those consequences systematically cared for". As we will demonstrate in this article, non-human animals (hereafter, "animals") may figure among the cared-for others in a public. Extending these insights, we argue that publics always involve non-human entities, and oftentimes the emergence and evolution of publics depend on multi-species entanglements.

To date, scholarship on publics has mostly emphasized speech and language. This emphasis on speech and language in political theory reinforces a tendency to ignore technologies and the material differences that they make to public life (Marres and Lezaun, 2011). In addition, a theoretical emphasis on discourse summarily excludes people who do not use speech and language to communicate, as well as non-human beings (Blue and Rock, 2014). More broadly, the prioritization of discourse seems to have detracted from recognition of the extent to which material bodies ultimately shape public life. By foregrounding embodiment, we attend to multi-species entanglements (Blue and Rock, 2011; Rock et al., 2014; Nading, 2013).

In our view, human bodies entangle with other species and with technologies so much that person-to-person interactions and transactions cannot explain much about the emergence and the evolution of publics, whereas Dewey (1991 [1927]) viewed transactions among people as foundational in these respects. Rather than emphasizing interactions between independent actors, we call attention to intra-actions (following Barad, 2003; Barad, 2007); and multi-species publics may arise from intraactions that include animals other than humans (Blue, 2015). Furthermore, more often than not (as per Appadurai, 1986), commodification imbues intra-actions. By that statement, we intend to underscore that public life may render non-human beings and human beings as interchangeable elements. Examples include the public presentation of human and non-human animals as symbols of an emergency, as we will demonstrate in what follows.

We will focus on the attention accorded to human-animal bonds during and following a disaster, as something of a test-case for the existence of multi-species publics, yet our theoretical contributions carry relevance for non-human animals other than people's pets. Displays and practices of solidarity often emerge in response to disasters, which are becoming more frequent and intense due to climate change. That said, enactments of solidarity necessarily remain partial and selective (Rock and Degeling, 2015). Therefore, responses to companion animals during and following disasters may assist in highlighting "alternative questions, neglected issues, marginalized perspectives and different possibilities... for policy purposes" than have prevailed thus far in public deliberations regarding climate change (Blue, 2016).

Throughout this article, we ask:

Given that millions of people lack the resources necessary to survive-never mind to thrive-what is the ethical basis for including people's pets when responding to disasters?

That line of inquiry has led us to ask a follow-up question:

What is the ethical basis for including people's pets when resolving the issues that disasters may generate or expose?

After discussing policy responses to pets in disaster situations, we outline our methodological approach. In concluding, we reiterate the main arguments and findings in relation to the two questions posed above.

\section{Background: people's pets, disasters, and One Health promotion}

The plight of pets in disasters first came to public attention after Hurricane Katrina struck the American city of New Orleans in August 2005. Many people refused to leave their homes without their pets because they could not bring their animal companions with them. Others did leave their pets behind, and the pets perished. Even as New Orleans remained under water, photographs illustrating the plight of pets and their people ricocheted around the world via media coverage. These photographs and the accompanying stories sparked a groundswell of public support for pets and their people across the United States and beyond. "The storm kicked up a universe of animal volunteers who went back and became involved in their communities", recalled one activist (cited in Grimm, 2015).

Legal changes followed from Hurricane Katrina and community-based activism. "The loss of thousands of pets to the hurricane encouraged lawmakers to rethink society's responsibility to animals", reported the Smithsonian Museum's magazine, a decade later (Fessenden, 2015). "Never before in my long congressional career have I received so much support and encouragement for a piece of legislation", recalled the American politician who introduced a bill that became known as PETS (cited in Grimm, 2015). The acronym "PETS" stands for the Pets Evacuation and Transportation Standards Act. Under PETS, local and state governments must submit written plans for accommodating households with pets or service animals, notably in emergency shelters; otherwise, these governmental agencies cannot qualify for disaster-relief funding from the federal government in the United States (Travers et al., 2017). In turn, the American legislation known as PETS became viewed in other jurisdictions as a model for an inclusive approach to disaster planning that supports protecting pets in and from disaster situations (Travers et al., 2017).

In this article, we elaborate on the insight that housing constitutes an infrastructure of care (Power and Mee, 2019). Accommodation of people's pets immediately following disasters and in emergency planning is important, yet insufficient. In the aftermath of disasters, people with pets and the pets themselves require more than short-term shelters: they require secure access to housing that meets their needs. The pre-disaster distribution of 
economic resources and social support influence post-disaster housing outcomes for people and pets (Travers et al., 2017). We need to consider who cares for whom, whenever disasters displace people and their pets. We also need to consider what happens following disasters that displace people and their pets.

Housing for multi-species families matters for the promotion of One Health, or so we will argue. As a concept, One Health emerged to take into account complex interdependencies among humans, animals, and environments, with particular concern for zoonotic infections that can spread from animals to humans (Bresalier et al., 2015; Rock et al., 2009). To date, social scientists have had little to do with One Health (Friese and Nuyts, 2017), but that situation is changing rapidly (Craddock and Hinchliffe, 2015; Brown and Nading, 2019). As social scientists become more engaged with One Health, more emphasis is being placed on social inequality. Zoonotic infections remain important, but to understand their spread, social scientists have drawn attention to social inequality as a driving force.

More generally, equitable outcomes-for humans and animals -hinge on access to resources and on the capacity to transform these resources (Rock, 2016). Along these lines, housing represents a crucial resource for human health (Dunn, 2000). As for animals kept as pets, surrenders often result when people move and cannot bring their pets to their new housing; and euthanasia often results from such surrenders (Coe et al., 2014). Whereas the loss of any pet can be devastating, feelings of grief, guilt, and isolation may compound when people must relinquish a pet so that they may secure housing (Toohey and Rock, 2018; Fox and Ray, 2019).

Proponents of a field known as "health promotion" have emphasized the distribution of resources and transformative capacity for decades, with support and participation from social scientists (Frohlich and Potvin, 1999; Mykhalovskiy et al., 2019). The Ottawa Charter for Health Promotion has a foundational status within this subfield (WHO, 1986). The Ottawa Charter proposes that health emerges from caring for one's self and others, yet proponents of health promotion have tended to assume that cared-for others are always human. Social scientists who work with public health have recently reinterpreted the emphasis placed on caring in the Ottawa Charter vis-à-vis climate change and the One Health concept (Poland et al., 2011; Buse et al., 2019; Rock and Degeling, 2016; Rock et al., 2015; Rock and Degeling, 2015). One Health refers to complex interactions and systems as the basis for well-being, for humans and animals in shared environments (Craddock and Hinchliffe, 2015). Along these lines, illumination regarding One Health promotion could come from the risks that disasters pose for people with pets and for the pets themselves (Travers et al., 2017).

With respect to the challenges and opportunities inherent to One Health promotion, our thinking has benefited from recent developments in conceptualizing solidarity as an ethical principle for public health. According to Prainsack and Buyx (2012; 2017), solidarity takes three main forms in practice: (1) interpersonal; (2) communitarian; and (3) institutional. Ideally, according to these authors, interpersonal solidarity gives rise to communitarian solidarity, and then communitarian solidarity gives rise to enactments of institutionalized solidarity that can be traced in changes to public policy (Prainsack and Buyx, 2017). In response, Dawson and Verweij $(2012$, p. 16) argued against the notion of a clear-cut distinction between interpersonal and communitarian solidarity. Rather, they supposed that "some idea of a group in which people share commitments to others underpins people's efforts to help one another" (Dawson and Verweij, 2012, p. 2); and we concur.

Prainsack and Buyx (2012) originally conceived of solidarity in ways that fell short of providing ethical guidance for One Health promotion. That was because they assumed that solidarity necessarily involved people helping other people. Yet, people often seek to help animals, too, because they feel a sense of affinity or kinship with these animals, and in order to help people who depend economically or emotionally on animals (Rock and Degeling, 2015; Toohey and Rock, 2018; Coulter, 2017). Accordingly, Prainsack and Buyx (2016, p. 493) revised their definition of solidarity as follows: "an enacted commitment to carry the costs (financial, social, emotional, and other contributions) of assisting others with whom a person or persons recognize similarity in a relevant respect" (see also Prainsack and Buyx, 2017). That is the definition of solidarity to which we subscribe in what follows.

\section{Methodology}

Engaged scholarship, for us, means that we recognize ourselves as living with the dilemmas that we describe in this article (Agar, 2006; Low and Merry, 2010). Accordingly, we have sought to articulate these dilemmas and to contribute constructively to their resolution (as per Haraway, 2004 [1992]). This article derives from case-study research that took place within the Canadian province of Alberta. Approximately half of all households in this setting include pets, and about one-third include dogs (Perrin, 2009; Rock, 2013).

In June 2013, massive flooding took place along the waterways throughout southern Alberta. The floodwaters inundated central Calgary, the largest city in the region, as well as smaller towns along several rivers in the vicinity. Thousands of homes were severely damaged and deemed unfit for habitation. Both authors lived through the June 2013 floods; hence our understanding the events and the context stems partly from direct experience, and partly from indirect forms of witnessing. For example, we learned about the flooding and its impacts in conversations with other people, as well as from stories that reached us via mainstream media, social media, or both (as per Slack, 2006; Marres and Moats, 2015). Therefore, we took an ethnographic approach to this case-study research, by considering how these stories were produced, received, and circulated (as per Altheide, 1987). In doing so, we drew explicitly and implicitly on our own experience, and we also questioned our assumptions in discussions with another (as per Agar, 2006).

Prior to preparing this article, previous research within the team had highlighted a perennial lack of housing for lowerincome Calgarians along with their cats and dogs (Graham et al., 2019; Graham and Rock, 2018; Graham et al., 2018; Toohey et al., 2017; Toohey and Rock, 2018; Toohey and Krahn, 2017). Furthermore, policy debates culminating in reforms to The City of Calgary's rental housing policy have ignored this issue (Levanda et al., 2020). Nonetheless, we recalled a groundswell of efforts to accommodate people and their pets, during and immediately following the floods of June 2013. For the purposes of this article, therefore, we set out to document the emergence, the extent, and the duration of focused attention in mass media on accommodation for multispecies families.

Researchers and practitioners in disaster management often distinguish heuristically between phases that together form a cycle, or a spiral: (1) response; (2) recovery; and (3) preparedness (Patterson et al., 2010). Accordingly, we identified and classified media sources according to these phases (see Table 1). Given that texts inscribe concerns and values (as per Latour and Bastide, 1986; Marres and Lezaun, 2011; Altheide, 1987), we analyzed media coverage to trace the extent to which accommodating human-animal bonds figured in responses to, recovery from, and preparedness following the 2013 floods. 


\begin{tabular}{|ll|}
\hline Table 1 Media sources by disaster & phases. \\
\hline Disaster phase & Media Sources \\
\hline Disaster response & 1. The Canadian Press (2013b) \\
Disaster recovery & 2. Daro (2013) \\
& 1. CBC News (2013) \\
& 2. The Canadian Press (2013a) \\
& 3. Graveland (2013) \\
4isaster preparedness & 1. National Post (2015) \\
& 2. Mclntosh (2015) \\
& 3. Klingbeil (2015) \\
& 4. Cole (2019b) \\
5. Cole (2019a) & 6. Toohey (2019)
\end{tabular}

\section{Findings}

Disaster response. One of the most memorable media stories from the June 2013 floods featured a housecat named Momo. The headline read, "Swimming sensation Momo the cat escapes Alberta flood" (The Canadian Press, 2013a), and the text below contained several photographs, which together resembled a storyboard.

The first photograph showed Momo, swimming by himself. The caption read, "Experts say most cats are capable swimmers, and Momo the cat was put to the test after the Highwood River began sweeping away the truck she and her guardian were in" (The Canadian Press, 2013a).

The second photograph showed the blond head of a young man, sticking out of the window at the back of the truck's cab. According to the young man's mother, "He couldn't get out, so he had to smash out the back window with his elbow and, of course, the cat was trying to beat him out" (cited in The Canadian Press, 2013a).

The third photograph showed the young man perched in the back box of a truck, directly behind the cab, and holding Momo in his arms. Already, truck's engine and most of the cab were under water.

The next photograph to be taken would have been of Momo swimming on his own (as per above). That is because Momo jumped into the water first, and the young man followed (The Canadian Press, 2013a). "I swam behind Momo and wherever Momo went that's where I was going. I'm just glad he went for shore", recalled the young man. Had Momo not leapt from the sinking truck into the floodwaters, "I wouldn't have got out. I wouldn't have bailed", he said (cited in Graveland, 2013).

The fourth photograph in the story showed the young man swimming directly behind the cat, against the backdrop of the truck. By then, the truck was mostly submerged.

The fifth photograph also showed Momo and the young man, both still swimming; but the truck was no longer in the frame. Momo was "swinging her tail back-and-forth and using it as a rudder, as an alligator does" (The Canadian Press, 2013a).

The sixth photograph showed the young man standing between two men who had come to the rescue. The caption read, "Rescuers come to the aid of man and cat" (The Canadian Press, 2013a). By then, the water level was almost waist-high on all three people. One of the responders appeared to be a community volunteer, as he wore a short-sleeved t-shirt and blue jeans held up by a leather belt, fastened by a cowboystyle belt buckle. Just as the photograph was taken, this volunteer was passing a long-sleeved fleece jacket to the young man, suggesting that the volunteer was literally giving the young man the clothes off his back. Meanwhile, the young man was passing the cat to the other responder, who wore orange overall-style waders over a long-sleeved shirt, implying that he had an official role. The drenched cat was visibly upset: Momo had placed his front two paws on the responder's overalls, near the man's neck; and the cat's ears were pinned back.

The seventh photograph also featured the two responders, Momo, and the young man. This time, the neighborly responder held Momo away from his own body, for his own protection, with the fleece jacket wrapped around Momo. One of Momo's front paws extended up towards the rescuer's face and neck. As stated by the caption, "Momo appeared to be less than impressed with the ordeal" (The Canadian Press, 2013a).

The eight and final photograph in the series showed the young man a week later, in dry clothing, standing on dry land, and holding Momo in his arms.

We regard the young man's rescue of Momo from their shared apartment as an enactment of solidarity, fueled by the young man's feelings of kinship with Momo (as per Rock and Degeling, 2015). The media story explained that, as the flood began, the young man bee-lined from his jobsite to his apartment because he felt compelled to rescue Momo. He reportedly told his mother, "Mom, it's like my baby, you know, I couldn't live with myself if something happened" (cited in The Canadian Press, 2013a). Some people have questioned this response, he reported. "Lots of positive and a couple of negative reactions: 'For a cat? Really?' But it's a member of the family so what can you do?" (cited in Graveland, 2013). The accompanying text revealed that the young man was staying with his parents, with Momo in tow (The Canadian Press, 2013a). His mother told the journalist that Momo had been "pretty scared and stressed", but the cat "was quite at home now" (cited in The Canadian Press, 2013a). We infer that the parents' efforts to act in solidarity with their son, by providing him with housing, had extended to his cat (as per Rock and Degeling, 2015).

The very fact that Momo's name became known to us signals that the rescue of this housecat resonated beyond a single humananimal dyad. We surmise that the responders acted on "a collective commitment...to assist others" who were linked together "by a shared situation" (Prainsack and Buyx, 2012, p. 347)-so much so that a man's cat could not be ignored. Acting in solidarity with the young man, in other words, meant helping him with rescuing his cat (as per Rock and Degeling, 2015). Even so, the responders risked being scratched or bitten by the frightened cat.

Beyond the familial and communitarian responses to Momo's plight, this story prompted a public response, via mass media and social media. By the time the Canadian Broadcasting Corporation ceased to post comments on this story, a total of 82 comments had been logged on its website alone; and some of these posts pointed to additional commentary on other websites (see The Canadian Press, 2013a). In addition, copies of these photographs circulated far and wide through media outlets, in addition to social media. As far away as the United States and the United Kingdom (Daro, 2013; The Canadian Press, 2013a), Momo gained renown "as a symbol of hope amidst devastation" (Graveland, 2014).

Disaster recovery. Momo was one of thousands of pets whom people rescued during the June 2013 floods, and each of these 
animals ultimately returned to their families, became rehomed, or ended up dead. The Canadian Broadcasting Corporation reported that evacuees could bring their pets for temporary accommodation, free of charge, to shelters operated by local governments and charities (CBC News, 2013). This particular story also named a series of veterinary clinics, grooming services, and kenneling services where people could take their pets on temporary basis, for safekeeping (CBC News, 2013). Other media stories emphasized that animal shelters were full to overflowing, so anyone who could retrieve their pets should do so without delay (The Canadian Press, 2013b).

Media reports like these served as a public service announcements because the journalists helped to coordinate a collective response that went beyond face-to-face communities and networks. Meanwhile, social media carried pledges of assistance for people, pets, or both from within the disaster zone and well beyond. All the while, donations came in, and some donors earmarked funds to help care for people's pets. Yet this particular multi-species public, which focused attention on accommodating people's pets, did not last long.

The fact that Momo's story had a happy ending could have influenced the denouement of public concern for accommodating people alongside their pets in the wake of the June 2013 flood. As Christmas approached, the headline for a follow-up story about Momo declared, "Internet celebrity Momo the cat living the quiet life after surviving Alberta flood" (Graveland, 2013). This goodnews story revealed that the young man was still staying in his parents' home, along with Momo, whom the mother described as a "grand-kitty" (cited in Graveland, 2013).

A full year after the flooding, the parents continued to house the young man together with Momo. In June 2014, the photographer received an award nomination for the images of Momo's rescue from the June 2013 flood, which prompted another follow-up story in local media. Momo's young man was interviewed "at his home", while his mother was "playing with Momo in the background" (Graveland, 2014). Meanwhile, the young man's rugby teammates continued to tease him about Momo's rescue and the subsequent media attention. "They call me Kitty Momo", he said (cited in Graveland, 2014). So-called boomerang moves have become commonplace among members of the so-called millennial generation; but not all millennials have parents who are willing or able to accommodate their adult children, along with their pets (Graham et al., 2019).

During the recovery period following the June 2013 floods, demand for pet-tolerant rental housing outstripped supply, by orders of magnitude (Graham and Rock, 2018). Fewer than 10\% of rental units that were advertised online in Calgary would allow any pets at all, and fewer still would accommodate dogs (Graham and Rock, 2018). Online advertisements for pet-tolerant rental units during the recovery period tended to be more expensive than for pet-intolerant rental units, due to a combination of rental prices, pet-specific damage deposits, and monthly surcharges for the privilege of keeping pets (Graham et al., 2018) In addition, landlords frequently imposed restrictions on dog size and breed, in their advertisements and when negotiating with prospective tenants (Graham and Rock, 2018; Graham et al., 2018).

Tenants and would-be tenants adopted several strategies to find and keep rental housing. To keep their pets with them, meanwhile, many tenants stayed in housing and neighborhoods that they perceived to be unsafe (Graham et al., 2019; Toohey and Rock, 2018). Of note, many tenants were obliged to live in basement suites that were illegal at the time. Moreover, some of these basements qualified as fire hazards (Levanda et al., 2020), and some had been damaged by the floods. Out of desperation, some would-be tenants posted pleas online (Graham and Rock, 2018).
In the wake of the June 2013 floods, policy-makers did not act to alleviate the shortage of pet-friendly rental housing. The City of Calgary did take steps to legalize "secondary suites" in basements and garages, under certain conditions; nonetheless, the difficulties faced by tenants with pets did not register in public debates, nor in the eventual reform of policy (Levanda et al., 2020). The Government of Alberta still allows landlords to ban pets from rental units, if they so choose, and to impose surcharges on tenants with pets (Graham and Rock, 2018). Meanwhile, the Government of Canada continues to privilege homeownership in its policies, which relegates lower-income people to less-desirable housing in the rental market (Suttor, 2017; Dunn et al., 2006; Carroll and Jones, 2000; MacLeod et al., 2017). These policies have combined to compound risks among people who feel strongly attached to their pets, yet who have little by way of economic, familial, or community support (Toohey and Rock, 2018; Toohey et al., 2017; Graham et al., 2019).

Disaster preparedness? Disasters comprise an arena in which planners and practitioners seek to enhance what has become known as "preparedness" (Lakoff, 2007). Preparedness "involves a coordinated and continuous process of planning and implementation that relies on measuring performance and taking corrective action" (Nelson et al., 2007, s9). In public health, preparedness "should include a full range of prevention, mitigation, and recovery activities, not just those designed to enable responses to events" (Nelson et al., 2007, s9). Besides enhancing the skills and capabilities of responders, preparedness ought to foster resiliency in communities and populations (Nelson et al., 2007, s9; Patterson et al., 2010; Buse et al., 2019).

As part of preparedness, disaster managers must "anticipate reactions from diverse publics", which tend to be "registered and amplified through television and other modern communication technologies" (Blue and Rock, 2011, p. 356). Hurricane Katrina taught disaster managers to view people's pets as a concern and as an opportunity to bring people together (Travers et al., 2017). Indeed, people's pets have become so prominent in media coverage of disasters that one journalist wrote, "As with most disasters, the floods that have washed out Calgary and large parts of southern Alberta have produced an animal hero" (Daro, 2013).

Disaster managers have learned that inadequate planning for pets puts people in peril, not to mention the pets themselves (Travers et al., 2016). Pet-friendly housing, however, has yet to receive much attention in the scholarly literature on disaster preparedness (Travers et al., 2017; Graham and Rock, 2018). Nevertheless, wherever warranted by the popularity of pets, disaster preparedness ought to include an adequate supply of petfriendly housing that is accessible, affordable, and appropriate. Otherwise, displaced people and their pets will have nowhere to go, and multi-species families may face eviction, homelessness, and pet surrenders.

To date, disaster managers continue to frame preparedness for pets as an individual obligation, not as a collective responsibility (Travers et al., 2016). No matter how much citizens plan ahead with their pets in mind, however, the presence of pets gives rise to moral dilemmas during and after disasters (Travers et al., 2017; Heath and Linnabary, 2015). People with pets, for starters, must make difficult decisions. They may take some pets with them, while leaving others behind; or they may stay with their pets, even after being advised to evacuate; or they may enter dangerous situations to retrieve their pets, as occurred with Momo. In June 2013, the water levels rose so quickly across southern Alberta that any amount of advance planning by the young man to whom Momo belonged would have been futile. In our view, media coverage featuring Momo inspired a public response in part 
because community responders were willing-if not fully prepared-to help both this cat and the young man to whom Momo belonged. This person-pet dyad found housing through family connections, but many multi-species families were torn apart.

The lack of an institutionalized response to housing insecurity among people with pets came into focus through two media stories that appeared some time after the June 2013 floods. The first surfaced more than two years after the flooding, in 2015. This story revolved around an older woman who, solely because she refused to part with her kitten, found herself faced with eviction (National Post, 2015). A follow-up story reported, "Despite public support, still no housing for senior with kitten” (McIntosh, 2015). In this case, "public support" included "offers from strangers to take Samantha [the kitten] in" (McIntosh, 2015). Yet as the journalist put it, the woman in question "says she just needs an affordable home" (McIntosh, 2015). She told the journalist, "Now, if only someone could come up with a place to live" (cited in McIntosh, 2015). Ultimately, this woman was able to move with her kitten into a subsidized apartment (Klingbeil, 2015), in one of only a handful of buildings in Calgary where cats are permitted (Toohey et al., 2017; Toohey and Krahn, 2017; Toohey and Rock, 2018).

Of note, the woman at the center of this media story explicitly called for public solidarity, at the level of policy reforms, beyond well-meaning assistance from strangers (as per Rock and Degeling, 2015; Toohey and Rock, 2018). "I desperately need a place to live but I would really love to see the rules changed for everybody in the province [of Alberta]", she told the journalist (cited in McIntosh, 2015). She elaborated, "I'd like to see them put a law in that they cannot refuse you to have a pet". Indeed, Canada lags beyond countries such as France, Greece, and the United States in offering legal protection to tenants with pets (Toohey and Krahn, 2017).

Housing insecurity among older adults with pets in Calgary became the subject of another media story more than five years after the June 2013 floods. This time, the older adult was a man; and the pet in question was a dog, named Jellybean. A local newspaper reported that this man had been told to vacate his rental unit by 1 February 2019 (Cole, 2019b). "So far, every property manager he has called has turned him away, citing policies banning all pets or larger dogs" (Cole, 2019b). The man recalled one of these rejections, as follows:

And everything was fine until I mentioned the dog... and I said, "how come everybody hates dogs all of a sudden?" He [the property manager] says, "I love dogs". It kind of threw me a bit, because if you love dogs, let a dog in (cited in Cole, 2019b).

In this case, engaged research helped to bring the story to public attention and to frame the story in terms of social injustice. Toohey, whom the journalist identified as "the scientific coordinator of the Brenda Strafford Center on Aging at the University of Calgary", explained that this man's "struggle to find an affordable home for him and his pet is a reflection of a broader problem for seniors" (cited in Cole, 2019b). With reference to recently-completed qualitative research (see Toohey et al., 2017), she continued, "Housing came up quite regularly, especially when I was speaking with those service providers who really focus on the facets of our older population who are struggling and for whom I heard pets described as things like a lifeline, a reason to get out of bed every day" (cited in Cole, 2019b).

Two days later, the journalist filed a follow-up story with a happy ending. After learning about the situation from the original media coverage, a citizen had come forward who was prepared to rent a basement suite to this man, at a manageable rent, where his dog would be welcome (Cole, 2019a). Furthermore, the man could contribute to upkeep of the property by gardening, a preferred pastime. "It's a great relief", he told the journalist (cited in Cole, 2019a). "You're sitting here wondering, wondering what you're going to do. Now it's solved with a lot of help from different people".

We regard this man's gesture towards a resolution that came about as a result of media attention and engaged research as a prime example of a multi-species public in action. Nonetheless, as Toohey said on that occasion, "solutions are still needed for the many other seniors who are unable to find subsidized or affordable housing for themselves and their animal companion" (cited in Cole, 2019a). Ultimately, Toohey (2019) pointed to the shortage of pet-friendly rentals as a systemic issue, whose impacts extend beyond older adults and their animal companions: "Alberta's housing legislation falls short of protecting tenants' rights to have pets, and this must change".

\section{Discussion}

This article has advanced a posthumanist orientation to health promotion by calling attention to human-animal bonds as a policy issue for disaster response, recovery, and preparedness. Humanism has predominated in health promotion, and more generally in public health (Rock et al., 2014). Even so, humananimal bonds and the welfare of animals have begun to register as important concerns (Rock, 2017; Degeling et al., 2016). The concept of healthy publics, as outlined by Hinchliffe and colleagues (Hinchliffe et al., 2018), aligns with the emphasis placed in the field of health promotion on collaborative decision-making in communities and governments. We aspire to help in ensuring that engaged research and public experimentation regarding healthy publics develops in ways that acknowledge human, as well as non-human agency.

Dewey's classic scholarship on the nature of publics and on pragmatic methodologies for studying the emergence and erosion of publics did not anticipate any roles for animals. He extended membership in a public to "all those who are affected" by actions and by inaction, and who consequently become the recipients of care through systemic reforms (Dewey, 1991 [1927], p. 27). Previously, we have shown that as people's attachments to pets and animal welfare have developed into public concerns, people's pets and animals of all kinds may become central figures in publics (Blue, 2015; Blue and Rock, 2011; Blue and Rock, 2014). Whether certain animals or types of animals feature prominently in the emergence and evolution of a public, or not, human bodies entangle with non-human life to such an extent that all policies and systems carry implications for animals (Rock, 2016). In this article, we have argued that a public does not become healthier than otherwise would be the case by excluding animals. That said, we do not believe that multi-species publics always qualify as healthy publics.

From the research underpinning this article, we infer that multi-species publics become more durable, more equitable, and healthier whenever policy statements, planning documents, and implementation strategies enact solidarity in ways that include both people and animals. Following on from Hurricane Katrina, the passage of federal legislation known as PETS systematically addressed the relevance of human-animal bonds for disaster response in the United States and has become a model policy internationally (Travers et al., 2017). This article suggests that accommodating human-animal bonds mattered more in responses during and immediately following a disaster than in disaster recovery and preparedness. In the fullest sense, disaster recovery and preparedness require policy changes. At the same time, disasters may highlight institutional gaps. 
In our case-study investigation, we focused on housing insecurity as a policy issue that affects people with pets and the pets themselves. To do so, we focused attention on media coverage that ensued from a major flood in June 2013. This disaster unfolded as a public experiment, in which we became engaged as citizens and as social scientists, and to which we turned retrospectively for analytic purposes. As the floodwaters subsided, we found evidence in media coverage of familial and communitarian solidarity towards people and their pets. Nevertheless, media coverage about the flood did not emphasize the long-standing lack of affordable housing for multi-species families. Subsequent media attention did frame housing for people with pets as an issue for public policy, but without calling attention to housing security for people and pets as a contributor to disaster preparedness and resilience. At the time of writing, housing insecurity for multi-species families remains at an impasse, and policy debates about housing insecurity continue to ignore multi-species families.

\section{Conclusion}

By foregrounding selectivity enactments of more-than-human solidarity (Blue and Rock, 2011; Rock and Degeling, 2015), we have invited further questioning of humanist assumptions about the nature of publics. Following Dewey (1991 [1927]), we have argued that publics take shape whenever existing institutional arrangements cannot settle issues. Dewey, however, maintained that publics were essentially human creations. By contrast, we have pointed to the material existence of - and a theoretical basis -for multi-species publics (Blue, 2015; Blue and Rock, 2014; Blue and Rock, 2011; Rock, 2017; Instone and Sweeney, 2014). The depths to which many people care for and about pets makes possible the creation of certain publics, which would not otherwise come into existence at all. A key challenge, as engaged researchers ourselves, is to work productively with affinities for animals while also responding effectively to inequities among people. Paradoxically perhaps, disasters may represent "public experiments" through which matters such as these can be brought into focus as political issues, and then redressed in novel ways.

\section{Data availability}

In this article, media reports served as the primary sources. We have cited these reports accordingly.

Received: 19 December 2019; Accepted: 27 May 2020;

Published online: 06 July 2020

\section{References}

Agar M (2006) An ethnography by any other name... Forum: Qual Soc Res 7(4), http://www.qualitative-research.net/index.php/fqs/article/view/177

Altheide DL(1987) Ethnographic content analysis. Qual Sociol 10(1):65-77

Appadurai A (1986) Introduction: commodities and the politics of value. In: Appadurai A (ed) The social life of things: commodities in cultural perspective. Cambridge University Press, Cambridge, pp. 3-63

Barad K (2003) Posthumanist performativity: toward an understanding of how matter comes to matter. Signs: J Women Cult Soc 28(3):801-831

Barad K (2007) Meeting the universe halfway: quantum physics and the entanglement of matter and meaning. Duke University Press, Raleigh, NC

Blue G (2015) Multi-species publics in the Anthropocene: from symbolic exchange to material-discursive intra-action, In: Human Animal Research Network Editorial Collective (ed) Animals in the Anthropocene: critical perspectives on non-human futures. Sydney University Press, Sydney, pp. 165-174

Blue G (2016) Framing climate change for public deliberation: what role for interpretive social sciences and humanities? J Environ Policy Plan 18 (1):67-84

Blue G, Rock MJ (2011) Trans-biopolitics: complexity in interspecies relations. Health: Interdiscip J Soc Study Health, Illn Med 15(4):353-368
Blue G, Rock MJ (2014) Animal publics: accounting for heterogeneity in political life. Soc Anim 22(5):503-519

Bresalier M, Cassidy A, Woods A (2015) One Health in history, In: Zinsstag J, Schelling E, Waltner-Toews D, Whittaker M, Tanner M (eds) One Health: the theory and practice of integrated health approaches. CABI, Oxfordshire, pp. $1-15$

Brown H, Nading AM (2019) Human animal health in medical anthropology. Med Anthropol Q 33(1):5-23

Buse CG, Poland B, Wong J, Haluza-Delay R (2019) 'We're all brave pioneers on this road': a Bourdieusian analysis of field creation for public health adaptation to climate change in Ontario, Canada, Critical Public Health, https:// doi.org/10.1080/09581596.2019.1682123

Carroll BW, Jones RJ (2000) The road to innovation, convergence or inertia: devolution in housing policy in Canada. Can Public Policy 6(8):277-293

CBC News (2013) Furry flood victims rescued from rising waters (edn). https:// www.cbc.ca/news/canada/calgary/furry-flood-victims-rescued-from-risingwaters-1.1300542

Coe JB, Young I, Lambert K, Dysart L, Nogueira Borden L, Rajić A (2014) A scoping review of published research on the relinquishment of companion animals. J Appl Anim Welf Sci 17(3):253-273

Cole Y (2019a) A great relief: Calgary senior secures a home for him and his beloved pet (edn). https://calgaryherald.com/news/local-news/calgary-seniorsecures-a-home-for-him-and-his-beloved-pet

Cole Y (2019b) In trade-off for a home he can afford, senior faces losing a beloved companion (edn). https://calgaryherald.com/health/seniors/seniors-strugglefinding-pet-friendly-housing-illustrates-wider-problem-expert-says

Coulter K (2017) Humane jobs: a political economic vision for interspecies solidarity and human-animal wellbeing. Politics Anim 3:31-41

Craddock S, Hinchliffe S (2015) One world, one health? Social science engagements with the one health agenda. Soc Sci Med 129:1-4

Daro IN (2013) Momo the cat becomes a celebrity after Alberta floods (edn). https://www.cbc.ca/news/canada/calgary/swimming-sensation-momo-thecat-escapes-alberta-flood-1.1370290

Dawson A, Verweij M (2012) Solidarity: a moral concept in need of clarification. Public Health Ethics 5(1):1-5

Degeling C, Lederman Z, Rock M (2016) Culling and the common good: reevaluating harms and benefits under the One Health paradigm. Public Health Ethics 9(3):244-254

Dewey J (1991 [1927]) The public and its problems. Ohio University Press, Athens, $\mathrm{OH}$

Dunn JR (2000) Housing and health inequalities: review and prospects for research. Hous Stud 15(3):341-366

Dunn JR, Hayes MV, Hulchanski JD, Hwang SW, Potvin L (2006) Housing as a socio-economic determinant of health: findings of a national needs, gaps and opportunities assessment. Can J Public Health 97(Suppl 3):S12-S17

Fessenden M (2015) How Hurricane Katrina changed pets' legal status: the loss of thousands of pets to the hurricane encouraged lawmakers to rethink society's responsibility to animals: Smithsonian Magazine. https://www.smithsonianmag. com/smart-news/law-takes-pets-more-seriously-after-hurricane-katrina180956138/ (Accessed 2 Oct 2019)

Fox M, Ray M (2019) No pets allowed? Companion animals, older people and residential care. Med Humanities 45(2):211-222

Friese C, Nuyts N (2017) Posthumanist critique and human health: How nonhumans (could) figure in public health research. Crit Public Health 27(3):303-313

Frohlich K, Potvin L (1999) Health promotion through the lens of population health: towards a salutogenic setting. Crit Public Health 9(3):211-222

Graham TM, Milaney KJ, Adams CL, Rock MJ (2018) "Pets negotiable": how do the perspectives of landlords and property managers compare with those of younger tenants with dogs? Anim 8(3):32

Graham TM, Milaney KJ, Adams CL, Rock MJ (2019) Are millennials really picking pets over people? Taking a closer look at dog ownership in emerging adulthood. Can J Fam Youth 11(1):202-227

Graham TM, Rock MJ (2018) The spillover effect of a flood on pets and their people: implications for rental housing. J Appl Anim Welf Sci 22(3):229-239

Graveland B (2013) Internet celebrity Momo the cat living the quiet life after surviving Alberta flood (edn). https://www.ctvnews.ca/canada/internet-celebrity-momothe-cat-living-the-quiet-life-after-surviving-alberta-flood-1.1593359

Graveland B (2014) 'They call me Kitty Momo': Celebrity cat and owner 1 year after Alberta flood (edn). https://www.ctvnews.ca/canada/they-call-me-kittymomo-celebrity-cat-and-owner-1-year-after-alberta-flood-1.1877950

Grimm D (2015) How hurricane Katrina turned pets into people, BuzzFeed News. https://www.buzzfeednews.com/article/davidhgrimm/how-hurricanekatrina-turned-pets-into-people

Haraway D (2004) The promises of monsters: a regenerative politics for inappropriate/d others. In: Haraway D (ed) The Haraway reader. Routledge, New York, NY, London, pp. 63-124. [1992]

Heath S, Linnabary R (2015) Challenges of managing animals in disasters in the US. Animals 5(2):173-192 
Hinchliffe S, Jackson MA, Wyatt K, Barlow AE, Barreto M, Clare L, Depledge MH, Durie R, Fleming LE, Groom N (2018) Healthy publics: enabling cultures and environments for health. Palgrave Commun 4(1):57

Instone L, Sweeney J (2014) The trouble with dogs: 'animaling' public space in the Australian city. Contin: J Media Cultural Stud 28(6):774-786

Klingbeil A (2015) Senior evicted over kitten finds cat-friendly home downtown (edn). https://calgaryherald.com/news/local-news/senior-evicted-over-kittenfinds-cat-friendly-home-downtown.

Lakoff A (2007) Preparing for the next emergency. Public Cult 19(2):247-271

Latour B, Bastide F (1986) Writing science-fact and fiction: the analysis of the process of reality construction through its application of socio-semiotic methods to scientific texts. In: Callon M, Law J, Rip A (eds) Mapping the dynamics of science and technology. MacMillan, London, pp. 51-66

Levanda A, Keough N, Rock M, Miller B (2020) Rethinking 'public' participation in the smart city, Canadian Geogr, https://doi.org/10.1111/cag.12601

Low SM, Merry SE (2010) Engaged anthropology: diversity and dilemmas. Curr Anthropol 51(S2):S203-S226

MacLeod T, Worton SK, Nelson G (2017) Bridging perspectives and balancing priorities: new directions for housing policy in Canada. Can J Community Ment Health 35(3):55-68

Marres N, Lezaun J (2011) Materials and devices of the public: an introduction. Econ Soc 40(4):489-509

Marres N, Moats D (2015) Mapping controversies with social media: the case for symmetry. Soc Media Soc 1(2):1-17

McIntosh E (2015) Despite public support, still no housing for senior with kitten (edn). https://calgaryherald.com/news/local-news/despite-public-supportstill-no-housing-for-senior-with-kitten

Mykhalovskiy E, Frohlich KL, Poland B, Di Ruggiero E, Rock MJ, Comer L (2019) Critical social science with public health: agonism, critique and engagement. Crit Public Health 29(5):522-533

Nading AM (2013) Humans, animals, and health: From ecology to entanglement. Environ Soc: Adv Res, 4(1):60-78

National Post (2015) 'I'm not getting rid of my kitty': Calgary senior chooses homelessness over giving up kitten (edn). http://news.nationalpost.com/ news/canada/im-not-getting-rid-of-my-kitty-calgary-senior-chooseshomelessness-over-giving-up-kitten

Nelson C, Lurie N, Wasserman J, Zakowski S (2007) Conceptualizing and defining public health emergency preparedness. Am J Public Health 97(Suppl 1):S9-S11

Patterson O, Weil F, Patel K (2010) The role of community in disaster response: conceptual models. Popul Res Policy Rev 29(2):127-141

Perrin T (2009) The facts and statistics on companion animals in Canada. Can Vet J 50(1):48-52

Poland B, Dooris M, Haluza-Delay R (2011) Securing 'supportive environments' for health in the face of ecosystem collapse: meeting the triple threat with a sociology of creative transformation. Health Promot Int 26(Suppl 2):ii202-ii215

Power ER, Mee KJ (2019) Housing: an infrastructure of care. Housing Stud 35 (3):484-505

Prainsack B, Buyx A (2012) Solidarity in contemporary bioethics: towards a new approach. Bioethics 26(7):343-350

Prainsack B, Buyx A (2016) Thinking ethical and regulatory frameworks in medicine from the perspective of solidarity on both sides of the Atlantic. Theor Med Bioeth 37(6):489-501

Prainsack B, Buyx A (2017) Solidarity in biomedicine and beyond. Cambridge University Press, Cambridge

Rock MJ (2013) Pet bylaws and posthumanist health promotion: a case study of urban policy. Crit Public Health 23(2):201-212

Rock MJ (2016) Multi-species entanglements, anthropology and environmental health justice. In: Kopnina H, Shoreman-Ouimet E (eds) Routledge handbook in environmental anthropology. Routledge, New York, NY, pp. 356-369

Rock MJ (2017) Who or what is 'the public' in critical public health? Reflections on posthumanism and anthropological engagements with One Health. Crit Public Health 27(3):314-324

Rock MJ, Adams CL, Degeling C, Massolo A, McCormack GR (2015) Policies on pets for healthy cities: a conceptual framework. Health Promotion Int 30 (4):976-986

Rock MJ, Buntain B, Hatfield J, Hallgrímsson B (2009) Animal-human connections, 'one health,' and the syndemic approach to prevention. Soc Sci Med 68 (6):991-995

Rock MJ, Degeling C (2015) Public health ethics and more-than-human solidarity. Soc Sci Med 129:61-67

Rock MJ, Degeling C (2016) Toward 'one health' promotion. In: Singer M (ed) A companion to the anthropology of environmental health. Wiley-Blackwell, West Sussex, UK, pp. 60-82

Rock MJ, Degeling C, Blue G (2014) Toward stronger theory in critical public health: insights from debates surrounding posthumanism. Crit Public Health 24(3):337-348
Slack JD (2006) The theory and method of articulation in cultural studies. In: Chen K-H, Morley D (eds) Stuart Hall: critical dialogues in cultural studies. Routledge, London, pp. 124-140

Suttor G (2017) Basement suites: demand, supply, space, and technology. Can Geographer 61(4):483-492

The Canadian Press (2013a) Swimming sensation Momo the cat escapes Alberta flood: Cat's swimming prowess put to the test during a dramatic escape from sinking truck (edn). https://www.cbc.ca/news/canada/calgary/swimmingsensation-momo-the-cat-escapes-alberta-flood-1.1370290

The Canadian Press (2013b) 'Your cat is here. Come now': Pet evacuees and wild animals saved from Alberta floods fill shelters (edn). https://nationalpost. $\mathrm{com} /$ news/canada/your-cat-is-here-come-now-pet-evacuees-and-wildanimals-saved-from-alberta-floods-fill-shelters

Toohey AM (2019) Opinion: Stan and Jellybean remind us of what it means to live in a humane society (edn). https://calgaryherald.com/opinion/columnists/ opinion-stan-and-jellybean-remind-us-of-what-it-means-to-live-in-ahumane-society

Toohey AM, Hewson JA, Adams CL, Rock MJ (2017) When places include pets: broadening the scope of relational approaches to promoting aging-in-place J Sociol Soc Welf 44(3):Article 7, http://scholarworks.wmich.edu/jssw/vol44/ iss $3 / 7$

Toohey AM, Krahn TM (2017) 'Simply to be let in': opening the doors to lowerincome older adults and their companion animals. J Public Health 40 (3):661-665

Toohey AM, Rock MJ (2018) Disruptive solidarity or solidarity disrupted? A dialogical narrative analysis of economically vulnerable older adults' efforts to age in place with pets. Public Health Ethics 12(1):15-29

Travers C, Degeling C, Rock M (2016) The cat's cradle of responsibility: assigning and taking responsibility for companion animals in natural disasters. Australas J Disaster Trauma Stud 20:61-67

Travers C, Degeling C, Rock M (2017) Companion animals in natural disasters: a scoping review of scholarly sources. J Appl Anim Welf Sci 20(4):324-343

WHO (1986) Ottawa Charter for Health Promotion. International Conference on Health Promotion. Ottawa, ON, Canada: World Health Organization. http:// www.phac-aspc.gc.ca (Accessed 20 Apr 2012)

\section{Acknowledgements}

Grants from the Canadian Institutes of Health Research (\#MOP-130569) and the Social Sciences and Humanities Research Council of Canada (\#430-2016-00078) contributed to the ideas presented in this article. MR's contributions benefited from visits to the Wellcome Center for Environments+Cultures of Health at the University of Exeter, and to the Australian Center for Health Engagement, Evidence, and Values at the University of Wollongong. MR and GB contributed equally to the development of the topic and the methodology. MR led the analysis and the writing process, with substantial input from GB.

\section{Competing interests}

The authors declare no competing interests.

\section{Additional information}

Correspondence and requests for materials should be addressed to M.R.

Reprints and permission information is available at http://www.nature.com/reprints

Publisher's note Springer Nature remains neutral with regard to jurisdictional claims in published maps and institutional affiliations.

Open Access This article is licensed under a Creative Commons Attribution 4.0 International License, which permits use, sharing, adaptation, distribution and reproduction in any medium or format, as long as you give appropriate credit to the original author(s) and the source, provide a link to the Creative Commons license, and indicate if changes were made. The images or other third party material in this article are included in the article's Creative Commons license, unless indicated otherwise in a credit line to the material. If material is not included in the article's Creative Commons license and your intended use is not permitted by statutory regulation or exceeds the permitted use, you will need to obtain permission directly from the copyright holder. To view a copy of this license, visit http://creativecommons.org/ licenses/by/4.0/

(C) The Author(s) 2020 